\title{
Genetic characterization of chytrids isolated from larval amphibians collected in central
} and east Texas

Thomas L. Marshall ${ }^{12}$, Carlos R. Baca ${ }^{1}$, Decio T. Correa ${ }^{2}$, Michael R. J. Forstner ${ }^{1}$, Dittmar Hahn $^{1}$, and David Rodriguez ${ }^{*}$

${ }^{1}$ Department of Biology, Texas State University, 601 University Dr., San Marcos, TX 78666, USA

${ }^{2}$ Department of Integrative Biology, University of Texas at Austin, 2415 Speedway, Austin, TX 78712, USA

*Corresponding author: Department of Biology, Texas State University, San Marcos, Texas, 78666, United States of America.

Tel.: +015122451020

E-mail address: drdz@txstate.edu 


\begin{abstract}
Chytridiomycosis, an emerging infectious disease caused by the fungal pathogen Batrachochytrium dendrobatidis $(B d)$, has caused amphibian population declines worldwide. $B d$ was first described in the 1990s and there are still geographic gaps in the genetic analysis of this globally distributed pathogen. Relatively few genetic studies have focused on regions where $B d$ exhibits low virulence, potentially creating a bias in our current knowledge of the pathogen's genetic diversity. Disease-associated declines have not been recorded in Texas (USA), yet $B d$ has been detected on amphibians in the state. These strains have not been isolated and characterized genetically; therefore, we isolated, cultured, and genotyped $B d$ from central Texas and compared isolates to a panel of previously genotyped strains distributed across the Western Hemisphere. We also isolated other chytrids not known to infect amphibians from east Texas. To identify larval amphibian hosts, we sequenced part of the COI gene. Among $37 \mathrm{Bd}$ isolates from Texas, we detected 19 unique multi-locus genotypes, but found no genetic structure associated with host species, Texas localities, or across North America. Isolates from central Texas exhibit high diversity and genetically cluster with $B d$-GPL isolates from the western U.S. that have caused amphibian population declines. This study genetically characterizes isolates of $B d$ from the south central U.S. and adds to the global knowledge of $B d$ genotypes.
\end{abstract}

Keywords: Batrachochytrium dendrobatidis; pathogen dynamics; MLST; culture; genotyping; anuran host 


\section{Introduction}

Emerging infectious diseases (EIDs) - those that have recently increased in incidence, impact, virulence, geographic or host range, or have recently evolved — are a growing threat to human health and global biodiversity (Daszak et al. 2000, 2003). Over the past two decades, an increasing proportion of EIDs have been attributed to pathogenic fungi. These include powdery mildew on important crop plants, white-nosed syndrome in bats, snake fungal disease, colony collapse disorder in bees, and sea-fan aspergillosis in corals (Fisher et al. 2016; Fisher et al. 2012). Despite their immense economic and ecological impact, the genetic diversity of many of these fungi is still poorly understood (Fisher et al. 2016). None of these pathogens have been as devastating in their impact as Batrachochytrium dendrobatidis $(B d)$, the aquatic chytrid that induces chytridiomycosis, an epidermal infection in amphibians (Lips 2016).

$B d$, a member of the Rhizophydiales order of fungi, causes infections when its flagellated zoospores encyst in a host's skin and develop into zoosporangia (Letcher et al. 2006; Longcore et al. 1999). It was first described and attributed to disease outbreaks in the late 1990s (Longcore et al. 1999) and is now believed to be responsible for declines in amphibian populations dating back at least to the 1970s (Lips et al. 2004). Bd is found on every continent except Antarctica, is known to have infected over 700 species of amphibians, and has caused mass mortality events including species extinctions in Central and northern South America, the western U.S., Australia, and Spain (Berger et al. 1998; Bosch et al. 2001; Lips et al. 2006; Vredenburg et al. 2010). However, certain amphibian species and geographic regions have seemingly been unaffected by chytridiomycosis, even where $B d$ is present (Lips 2016).

Recent phylogenomic analyses of $B d$ have revealed multiple lineages that include the widespread global panzootic lineage (GPL), which is implicated in most disease outbreaks and 
can be further divided into a temperate clade ( $B d$-GPL1) and a tropical clade ( $B d$-GPL2). Other lineages include the putatively endemic and less virulent $B d$-Cape (found in South Africa and Spain), Bd-CH from Switzerland (Farrer et al. 2011), and Bd-Korea (Bataille et al. 2013). Sampling efforts have also led to the discovery of a strain in Japan that may be host specific (Goka et al. 2009) and Bd-Brazil (Jenkinson et al. 2016; Rodriguez et al. 2014; Schloegel et al. 2012), which genomic analyses have indicated is the earliest diverged $B d$ lineage currently known (Rosenblum et al. 2013).

Recently revealed diversity within the $B d$ clade, coupled with the fact that there are still several geographic gaps in our current knowledge of $B d$ genotypes (James et al. 2015), suggests additional diversity is yet to be discovered. However, relatively few studies have examined $B d$ genotypes from regions lacking population declines, potentially creating a bias in our knowledge of the pathogen's genetic diversity (Bataille et al. 2013). It is likely that $B d$ 's origin can be traced to a region in which amphibians have co-evolved with the fungus and where severe population declines and extinctions are not occurring (James et al. 2015). While recent work has begun to explore such regions of potential origin, genotyping in additional understudied areas is imperative and is facilitated by isolation and culturing of the fungus (Bataille et al. 2013; Jenkinson et al. 2016).

In the U.S., Bd-GPL has shown patterns of introduction and spread (Padgett-Flohr \& Hopkins 2009) and has caused host declines in the Sierra Nevada of California (Briggs et al. 2010; Wake \& Vredenburg 2008). On the other hand, long-term persistence and a lack of chytridiomycosis related host declines is also evident in the Midwest (Illinois) (Talley et al. 2015). Texas is a part of the south-central U.S. where, like the Midwest, no known chytridiomycosis-associated amphibian declines or extinctions have been detected. Studies have 
confirmed the presence of $B d$ in the eastern (Saenz et al. 2010) and central (Gaertner et al. 2012;

Gaertner et al. 2009a; Gaertner et al. 2009b; Gaertner et al. 2010) parts of the state, yet no strains from these regions have been genotyped or isolated thus far (James et al. 2015). While a lack of known $B d$-related population declines or extinctions in the area could be an indication that the pathogen has a long local history, other factors, such as climate or host resistance, may be responsible for attenuating disease outbreaks in the region. Studying the genetics of the fungus in Texas and its amphibian hosts is an important first step in understanding potential disease dynamics between amphibians and $B d$ in the region. Additionally, by genetically characterizing isolates from Texas and placing them in the context of a more broadly distributed panel of strains, we can begin to gain a more complete evolutionary picture of the $B d$ group, and perhaps a better understanding of the origins of its most virulent lineages. Therefore, the goal of this study was to isolate $B d$ from larval anurans in central and east Texas, genetically identify anuran hosts, and compare genetic variation among chytrid strains present in this region to those distributed across the Western Hemisphere.

\section{Methods and Materials}

\section{Host collection}

We collected anuran larvae from ponds in Travis, Hays, Bastrop, Kaufman, and Houston counties in central and eastern Texas from December 2015 to April 2016 (collection permit: SPR-0102-191) and stored them in $50 \mathrm{ml}$ Falcon tubes or new plastic containers with water from the collection site (Table 1). We transported all collected tadpoles, in Styrofoam containers kept cool with synthetic ice packs, to Texas State University where they were euthanized following animal care and use protocols IACUC2014116499 and IACUC2015121220. Each tadpole was 
given a unique identifier, and a tail clipping from each tadpole was preserved in $95 \%$ ethanol for DNA extraction.

Fungal isolation, culture, and cryopreservation

We excised the keratinized jaw sheaths and tooth rows from each tadpole and transferred them to $1 \%$ typtone agar petri dishes. We cleaned the mouthparts by dragging them through fresh agar and transferring them to $1 \%$ tryptone agar petri dishes with $200 \mathrm{mg} / \mathrm{ml}$ penicillin-G and 200 $\mathrm{mg} / \mathrm{ml}$ streptomycin sulfate for isolation of chytrids (Longcore 2000). We monitored the plates for growth of zoosporangia and active zoospores for up to two weeks. Once enough active zoospores were observed, we removed a section of the agar containing active zoospores to tryptone broth (16 g tryptone in 1,000 $\mathrm{ml}$ deionized water; autoclaved) to cultivate the isolate. Once there was a high density of active zoospores, we transferred a 1-ml aliquot of broth from each isolate to a $1.5-\mathrm{ml}$ centrifuge tube. We used a cryoprotectant solution consisting of $80 \mathrm{ml}$ tryptone broth, $10 \mathrm{ml}$ dimethyl sulfoxide, and $10 \mathrm{ml}$ fetal calf serum to preserve all chytrid isolates (Boyle et al. 2003). For each isolate, we briefly centrifuged (2,000 rpm) tryptone broth cultures in $1.5 \mathrm{ml}$ cryotubes, discarded the supernatant, and added $600 \mu \mathrm{l}$ of cryoprotectant. All isolates were given a serially numbered unique identifier (TXST - Texas State University) and were stored at $-80^{\circ} \mathrm{C}$ (Appendix I).

\section{Genetic methods}

To extract DNA, we centrifuged $1 \mathrm{ml}$ aliquots of live broth cultures, discarded the supernatant, and extracted DNA from the pellet using the Mammalian Tissue and Rodent Tail Genomic DNA Purification Protocol in the Thermo Scientific GeneJET Genomic DNA Purification Kit \#K0722 (Thermo Fisher Scientific, Inc.). We determined extraction success with gel electrophoresis using a 1\% agarose gel stained with GelRed (Biotium) in 1X TBE buffer. We 
performed conventional Polymerase Chain Reaction (PCR) on DNA from each successfully extracted isolate using primers for previously described multilocus sequence typing (MLST) markers (8009X2, BdC5, BdSc2.0, BdSc4.16, BdSc7.6, R6046, BdSC6.15) and the 18S rRNA gene (James et al. 2009; Jenkinson et al. 2016; Morehouse et al. 2003; Morgan et al. 2007; Schloegel et al. 2012) (Table S1). Amplifications were performed in $25 \mu$ l volumes consisting of 12.5 $\mu 1$ DreamTaq PCR Master Mix (2X) (Thermo Fisher Scientific, Inc.), $11.5 \mu 1$ nuclease free water, $0.25 \mu \mathrm{l}$ forward primer $(10 \mu \mathrm{M}), 0.25 \mu \mathrm{l}(10 \mu \mathrm{M})$ reverse primer, and $0.5 \mu 1$ template DNA. Thermocycling conditions consisted of an initial denaturing step of 2 min at $95^{\circ} \mathrm{C}$, then 32 cycles of $30 \mathrm{~s}$ at $95^{\circ} \mathrm{C}, 30 \mathrm{~s}$ at $52^{\circ} \mathrm{C}$ to $60^{\circ} \mathrm{C}$ depending on the primer pair (Table $\mathrm{S} 1$ ), $45 \mathrm{~s}$ at $72^{\circ} \mathrm{C}$, with a final extension of $10 \mathrm{~min}$ at $72^{\circ} \mathrm{C}$. We treated $5 \mu$ laliquots of PCR product with 2 $\mu 1$ ExoSAP-IT (Affymetrix Inc.) and incubated the total volume at $37^{\circ} \mathrm{C}$ for $15 \mathrm{~min}$ and then $80^{\circ} \mathrm{C}$ for $15 \mathrm{~min}$. Using each of the MLST primers, we performed cycle sequencing reactions using Big Dye v3.1 dye terminator (Applied Biosystems, Inc.). We incubated hydrated G-50 Sephadex $\left(2.6 \mathrm{~g} / 45 \mathrm{ml} \mathrm{H}_{2} \mathrm{O}\right)$ at room temperature for $30 \mathrm{~min}$, pipetted $400-\mu 1$ aliquots into individual wells in a filter plate, and centrifuged the plate at $3000 \mathrm{rpm}$ for 2 minutes to create a matrix through which cycle sequenced products were passed for purification. We dehydrated the purified cycle sequenced products, added $12 \mu \mathrm{l}$ of formamide, and incubated them for $3 \mathrm{~min}$ at $94^{\circ} \mathrm{C}$ and immediately cooled them to $4^{\circ} \mathrm{C}$. We electrophoresed the cycle sequenced products on an ABI 3100-Avant genetic analyzer (Applied Biosystems, Inc.) and trimmed and edited the resulting chromatograms using Geneious v9.1.5 (Kearse et al. 2012).

\section{Data Analysis}

We genotyped strains using reference sequences from Jenkinson et al. (2016). We then used a set of genotyped strains from across North and South America to perform comparative 
analyses and test for genetic structure across the Western Hemisphere. We limited our analyses to the Western Hemisphere owing to the relatively few number of strains sequenced at these same markers in the Eastern Hemisphere. These strains were selected from two previous studies that used at least six of the same genetic markers used in our study (Jenkinson et al. 2016; Schloegel et al. 2012). We excluded any strains that had been isolated from amphibians not found in the wild (this included animals from zoos, farms, and markets) for our analyses. The resulting dataset consisted of 177 strains, including the 37 Texas strains isolated in our study. Before calculating measures of genetic diversity, we divided our dataset into populations and subpopulations. These populations (and subpopulations) included temperate America (subpopulations: eastern North America, Texas, and western North America), tropical America (subpopulations: Panama, Brazil-GPL), $B d$-Brazil, and $B d$-Brazil/GPL hybrids. For each population and subpopulation, we calculated genotypic diversity and allelic richness using the $\mathrm{R}$ package POPGENREPORT (Adamack \& Gruber 2014). Next, we clone-corrected our datasets by removing identical genotypes from the same region. This resulted in a dataset that included the genotypes of 68 isolates, including 15 unique Texas isolates, at six MLST markers (Appendix 2). We then calculated gene diversity, or expected heterozygosity $\left(H_{\mathrm{E}}\right)$, and observed heterozygosity $\left(H_{\mathrm{O}}\right)$ using the R package ADEGENET (Jombart 2008) and calculated pairwise $\mathrm{F}_{\mathrm{ST}}$ values using GENEPOP (Rousset 2008).

To test for genetic structure among $B d$ isolates, we used STRUCTURE (Pritchard et al. 2000 ) with values of $K$ (number of genetic demes defined a priori) ranging from 1 to 12 and 5 iterations per $K$, using 500,000 Markov Chain Monte Carlo repetitions with a burn-in of 100,000. We determined the best number of populations by calculating $\Delta K$ (Evanno et al. 2005) using STRUCTURE HARVESTER (Earl \& Vonholdt 2012) and obtained average membership 
probabilities across all iterations per $K$ using the program CLUMPP (Jakobsson \& Rosenberg 2007). We performed an initial analysis with only our Texas isolates and their genotypes at all seven loci (8009x2, BdC5, BdSC4.16, BdSC7.6, R6046, BdSC6.15, BdSC2.0) to test for genetic structure within the state, followed by a second analysis combining the Texas isolates with the set of isolates from North and South America that had been sequenced and genotyped using at least six of the same markers (8009x2, BdC5, BdSC4.16, BdSC7.6, R6046, BdSC6.15). Both STRUCTURE analyses were performed using clone-corrected data.

\section{Host Sequencing and Identification}

We extracted DNA from tail muscle of collected tadpoles and toes of seven adult Rana berlandieri using the same extraction protocol described for $B d$. Conventional PCR was performed to amplify the cytochrome c oxidase I (COX1) gene (Table S1), and PCR products were purified and sequenced using the same methods described for $B d$ sequencing. Chromatograms were trimmed, edited and aligned in Geneious v 9.1.5 (Kearse et al. 2012). Using Clustal W, implemented through Geneious, we carried out a multiple sequence alignment of host sequence data $($ cost matrix $=$ clustalw, gap open cost $=15$, gap extend cost $=6.66)$. We used sequence similarity to assign anuran larvae to species and visualized the distance matrix (HKY) using a neighbor-joining topology. We included reference sequences from Pseudacris streckeri (GenBank accession no. KJ536156), Rana muscosa (GenBank accession no.

KU985709), R. clamitans (GenBank accession no. KY587195), and R. sphenocephala (GenBank accession no. KT388406) and newly generated reference sequences for adult $R$. berlandieri (GenBank accession no. MG969220 - MG969226). We suspected that some of the larvae belonged to these species based on geographic distribution and general morphology. Rana muscosa was chosen as an outgroup to Texas ranids. 


\section{Results}

We attempted to isolate $B d$ from a total of 140 tadpoles collected from sites in central, east, and north-central Texas (Fig. 1). From this total, we successfully cultured 41 chytrid isolates from 40 individual tadpoles comprising three host species. Of these 41 isolates, 37 were identified as $B d$ (Appendix 1). A total of 28 isolates have been characterized using all seven MLST markers, seven have been characterized at six loci, and two were characterized at five loci (Supplemental data). We were unable to amplify DNA of four isolates from two $R$. clamitans larvae using these markers but did amplify and sequence part of the 18S rRNA gene (Appendix 1). Using the NCBI BLAST search tool (Clark et al. 2016), we matched isolates TXST038 and TXST039 to Rhizophlyctis harderi (GenBank accession no. AF164272; match = 98\%, coverage $=100 \%$, E value $=0.0)$, which has recently been re-named Uebelmesseromyces harderi (Powell et al. 2015), TXST041 to Chytriomyces sp. (GenBank accession no. DQ536486; match =98\%, coverage $=100 \%$, E value $=0.0)$, and isolate TXST038 to Hyaloraphidium curvatum $($ GenBank accession no. NG_017172; match $=99 \%$, coverage $=100 \%$, E value $=0.0)$, all of which are species of chytrids not known to infect vertebrate hosts. Among the $37 \mathrm{Bd}$ isolates, there were 19 unique multi-locus genotypes (MLGs), and no MLGs were found at more than one collection site (Supplemental data).

A neighbor-joining topology (Fig. S1) revealed four distinct clades among potential hosts. Three clades were associated with $R$. clamitans, $R$. sphenocephala, and Pseudacris streckeri reference sequences. We suspected that some of our tadpole specimens were Rana berlandieri, although a COI reference sequence for this species was unavailable in GenBank. Thus, we sequenced seven $R$. berlandieri metamorphs from central, south, western parts of 
Texas (Appendix 1) to verify species assignments. All newly generated sequences were accessioned into GenBank (chytrid 18S, MG979804-MG979842; amphibian COI, MG969220MG969347).

\section{Measures of Genetic Diversity}

Gene diversity $\left(H_{\mathrm{E}}\right)$ among the clone corrected Western Hemisphere dataset was 0.506 and observed heterozygosity $\left(H_{\mathrm{O}}\right)$ was 0.370 . When all $B d$-GPL strains were divided into temperate and tropical groups, the temperate group had both higher $H_{\mathrm{E}}$ and $H_{\mathrm{O}}(0.402$ and 0.394 , respectively) than the tropical group ( 0.358 and 0.340 , respectively). Both groups had higher $H_{\mathrm{E}}$ and $H_{\mathrm{O}}$ than $B d$-Brazil ( 0.189 and 0.214 , respectively). While larger pooled populations had higher expected than observed heterozygosity, the subpopulations in our dataset tended to show the reverse trend (except for the GPL in western North America and southeastern Brazil). While Texas strains had lower $H_{\mathrm{E}}(0.348)$ than both eastern and western North American subpopulations, $H_{\mathrm{O}}(0.387)$ was intermediate between the two other North American regions. All North American subpopulations, including Texas, had higher $H_{\mathrm{O}}$ than Panama and southeastern Brazil, while Texas was the only North American subpopulation to have lower $H_{\mathrm{E}}$ than the GPL in southeastern Brazil. Panama had the lowest $H_{\mathrm{E}}$ and $H_{\mathrm{O}}$ of all GPL subpopulations. The temperate GPL had higher genotypic diversity (0.491) and allelic richness (1.81) compared to the tropical GPL ( 0.250 and 1.68 , respectively) and $B d$-Brazil ( 0.280 and 1.34 , respectively). Texas strains had lower genotypic diversity (0.405) and allelic richness (1.72) than eastern and western North American strains but displayed greater diversity in these measures than both tropical groups. Not surprisingly, the GPL/Bd-Brazil hybrid strains had higher measures of genetic diversity than all other groups (Table 2).

Cluster Analyses 
We performed a STRUCTURE analysis using seven loci on the 19 unique MLGs from Texas and did not detect population structure among these strains. We then conducted a STRUCTURE analysis on the combined dataset that included our Texas isolates, as well as additional Western Hemisphere genotypes from two previous studies (Jenkinson et al. 2016; Schloegel et al. 2012). For these analyses, we chose six MLST markers (r6046, BdSc6.15, $8009 \times 2$, BdC5, BdSC4.16, BdSC7.6) that had been sequenced in all three studies, thus we used 15 unique MLGs from Texas to compare against other New World isolates (Appendix 2).

Our STRUCTURE analysis indicated two to three genetically distinct demes in our dataset, with the highest $\Delta K$ value occurring at $K=2$ and second highest value at $K=3$ (Fig. S2). By using the already genetically identified isolates from the two previous studies as references, we determined that at $K=2$, our clusters corresponded to $B d$-GPL and $B d$-Brazil, while at $K=3$ substructure within the GPL corresponded to the two major clades within this group; namely $B d$ GPL1 and $B d$-GPL2 (Fig. 2A). However, we did not detect the presence of any $B d$-Brazil strains in Texas. We set an arbitrary threshold of $q=0.80$ for assigning strains to a particular cluster. Ambiguous strains that did not show strong support for a cluster included the putative GPL/BdBrazil hybrids, and two strains from Texas and three from Brazil that exhibited mixed support for the two GPL lineages. Pairwise $F_{\mathrm{ST}}$ values indicate much greater differentiation between $B d$ Brazil and all other populations, while Texas isolates show no difference from eastern North American isolates and relatively low differentiation (0.040) from isolates in western North America (Fig. 2B, Table S2).

\section{Discussion}


$B d$ has shown contrasting pathogen dynamics in North America (Briggs et al. 2010; Padgett-Flohr \& Hopkins 2009; Talley et al. 2015; Wake \& Vredenburg 2008), yet genetic information from cultured isolates is mainly restricted to the western and eastern U.S., leaving a large swath of the central U.S. without data on $B d$ genotypes, and thus information on strain types. We successfully isolated 37 chytrids identified as $B d$ and four other chytrids (three species) from three different amphibian host species native to central and east Texas. As a population, $B d$ isolates in this region do not show significant genetic differentiation from other North American isolates. Further, all $B d$ isolates collected in this study belong to the globally distributed $B d$-GPL, and none show genetic affinities to other major lineages (e.g. $B d$-Brazil, $B d$ $\mathrm{CH}, B d$-CAPE, or $B d$-Korea).

Our measures of genetic diversity across geographic regions in the Western Hemisphere are congruent with previous studies. James et al. (2009) found lower $H_{\mathrm{E}}$ and $H_{\mathrm{O}}$ among tropical GPL strains compared to temperate GPL strains using MLST markers. The latitudinal gradient in genetic diversity observed by Velo-Anton et al. (2012) from California to Panama is also congruent with our estimates. While North American strains have the highest measures of genetic diversity, Texas strains, which represent the southernmost group of North American strains in our dataset, tend to have slightly lower measures of diversity compared to the rest of the continent. Meanwhile, strains from Panama, the region closest to the equator in our dataset, have the lowest measures of diversity among the GPL. These trends could be reflective of a longer history of $B d$ in North America compared to the tropics, but we stress the need for further isolations from North America and genomic sequencing of these strains to draw stronger conclusions about the demographic history of $B d$ in the Western Hemisphere. 
The STRUCTURE results show support for two genetic demes within the GPL in Texas and throughout North America. These clusters, which are congruent to $B d$-GPL1 and $B d$-GPL2 (Rosenblum et al. 2013), are not structured by geography or host species. Of the 37 cultured Texas isolates, 32 appear to cluster with $B d$-GPL1 isolates. Three Texas isolates (TXST021, TXST026, and TXST035) cluster with Bd-GPL2, and two isolates (TXST012 and TXST033) exhibit some degree of assignment uncertainty between both $B d$-GPL groups (Fig. 2A). Evidence for hybridization between $B d$ lineages has been detected (Jenkinson et al. 2016; Schloegel et al. 2012), thus it is possible that these ambiguous strains could be the result of hybridization between the two $B d$-GPL lineages. The presence of the $B d$-GPL2, a mainly tropical clade (Rosenblum et al. 2013), in Texas is not a surprising discovery given that $B d$-GPL2 isolates have also been documented in isolated locations across North America, but its apparent rarity relative to the $B d$-GPL1 is consistent with the pattern seen across the continent (James et al. 2015). We should point out, however, that there is some ambiguity in assigning membership to these two sub-lineages within the GPL.

At the continental scale, $B d$ isolates in Texas genetically cluster with isolates responsible for severe outbreaks of chytridiomycosis in the western United States (Fig. 2B). This finding leaves us with a still unanswered question — why do these strains, which are genetically similar, cause disease and mortalities in some regions but not others? If the pathogen is genetically similar in these different regions, the other two points of the epidemiological triangle — host and environment - should be explored further. One intuitive explanation for the lack of known chytridiomycosis outbreaks in Texas is the influence of climate. Piotrowski et al. (2004) reported $B d$ 's optimal temperature range to be $17-25^{\circ} \mathrm{C}$ with a maximum threshold of $28^{\circ} \mathrm{C}$. In Texas, amphibians may be able to clear or reduce $B d$ infections before they become lethal coincident to 
hot summers, when temperatures regularly exceed $32^{\circ} \mathrm{C}$ (Nielsen-Gammon 2011). Indeed, $B d$ infections in Acris crepitans populations in central Texas have revealed a seasonal pattern in infection intensity, with peaks occurring in early spring followed by a decline throughout the summer months (Gaertner et al. 2012; Gaertner et al. 2009b). Additionally, temperatures in most parts of the state regularly exceed $B d$ 's thermal optimum for over six months of the year (U.S. climate data 2017). However, weather conditions cannot explain the lack of $B d$-associated morbidity in central Texas salamanders of the genus Eurycea, which dwell in cool, thermally stable aquifers and springs. While $B d$ infections in these salamanders have been documented (Gaertner et al. 2009a), symptoms of chytridiomycosis have not been detected in these populations despite several years of investigation (Bendik 2017; Bowles et al. 2006; Pierce et al. 2010). Differences in host resistance among and even within species have been documented (Savage \& Zamudio 2011; Woodhams et al. 2007), so it is possible that host species immunity plays a role in limiting the severity of disease outcomes in central Texas. The $B d$ strains isolated for this study will facilitate future studies necessary to disentangle the effects of both climate and host resistance on the dynamics of $B d$ infection in this region.

Our isolation and culturing efforts also recovered chytrids not known to infect vertebrate hosts, namely Uebelmesseromyces harderi (Rhizophydiales), Chytriomyces sp. (Chytridiales), and Hyaloraphidium curvatum (Monoblepharidales) (Fig. 1, Appendix 1). Zoosporic fungi of the phylum Chytridiomycota are generally saprobes or parasites of algae, plants, and invertebrates (Barr 2001). It is possible that these chytrids were present in the pond water from which these tadpoles were collected, and that they somehow persisted on the tadpole mouthparts despite our following established procedures to clean them by dragging through sterile agar several times (Longcore et al. 1999). Although studies of the morphology and systematics of $U$. harderi, 
Chytriomyces, and H. curvatum can be found in the literature, little appears to be known about the life history of these species (Forget et al. 2002; Letcher \& Powell 2002; Powell et al. 2015; Ustinova et al. 2000). Many chytrids have similar, uninformative morphological features (James et al. 2000), and what appear to be successful isolations may not represent Batrachochytrium species. Yet, these isolations and cultures are still useful in diversity discovery efforts, especially among the Chytridiomycota, a relatively understudied group of fungi (James et al. 2000). By sequencing isolates at the $18 \mathrm{~S}$ rRNA gene, we were able provide genetic and locality reference data for these species. Owing to the lack of data for environmental chytrids, we recommend genetic characterization of isolated cultures using general primers before-rather than in response to- - unsuccessful amplifications of $B d$ specific primers. These efforts will inform genetic databases and accurate curation of cryopreserved microscopic fungal collections.

Our investigation of genetic variation among $B d$ isolates from parts of Texas is an important first step in understanding disease dynamics between amphibians and $B d$ in this understudied region. We have gained a more complete picture of the distribution of $B d$ strains in this region and have begun to fill a large sampling gap for $B d$ isolates in North America. There are also important conservation implications to our understanding of chytridiomycosis dynamics in the region as well. Texas is home to 16 endemic amphibian species, many of which are federally listed as species of concern, and all of which are found in either the Edwards Plateau or the coastal prairies of Texas (Tipton et al. 2012). Knowledge of the $B d$ strains present in these regions can inform assessments of potential disease risks to host species in the face of continued climate change and habitat alteration.

\section{Acknowledgments}


We thank Abigail Romo, Charles and Rebecca Raleigh, and the Brackenridge Field Laboratory for access to collection sites. We dedicate this work to the memory of Jonathan Raleigh. We thank Dan Saenz, Trina Guerra, Stephen Roussos, Jeremy Weaver, Brandon Cranup, William Keitt, Jacob Owen, Madison Torres, Andrea Villamizar, Stephen Harding, Carlos Baca, Daniel Puckett, Edith Perez, Devlin Jackson, Anna Gates, and Stephanie Toussaint for assistance in the lab and field. We thank Ana V. Longo for reviewing an earlier version of this manuscript. This work was funded by a National Science Foundation Graduate Research Fellowship to TLM (DGE-1144466), a Texas State University Research Enhancement Program grant to DR, Start-up funds from Texas State University to DR, and a CAPES fellowship (BEX 1176/13-7) and Texas EcoLab Program grant to DTC. 


\section{References}

1. Adamack AT, Gruber B (2014) PopGenReport: simplifying basic population genetic analyses in R. Methods in Ecology and Evolution 5, 384-387.

2. Barr DJS (2001) Chytridiomycota. In: Systematics and Evolution (ed. McLaughlin DS, J.W.), pp. 93-112. Springer Heidelberg, Germany.

3. Bataille A, Fong JJ, Cha M, et al. (2013) Genetic evidence for a high diversity and wide distribution of endemic strains of the pathogenic chytrid fungus Batrachochytrium dendrobatidis in wild Asian amphibians. Molecular Ecology 22, 4196-4209.

4. Bendik NF (2017) Demographics, reproduction, growth, and abundance of Jollyville Plateau salamanders (Eurycea tonkawae). Ecology and Evolution 7, 5002-5015.

5. Berger L, Speare R, Daszak P, et al. (1998) Chytridiomycosis causes amphibian mortality associated with population declines in the rain forests of Australia and Central America. Proceedings of the National Academy of Sciences of the United States of America 95, 90319036.

6. Bosch J, Martinez-Solano I, Garcia-Paris M (2001) Evidence of a chytrid fungus infection involved in the decline of the common midwife toad (Alytes obstetricans) in protected areas of central Spain. Biological Conservation 97, 331-337.

7. Bowles BD, Sanders MS, Hansen RS (2006) Ecology of the Jollyville Plateau salamander (Eurycea tonkawae : Plethodontidae) with an assessment of the potential effects of urbanization. Hydrobiologia 553, 111-120.

8. Boyle DG, Hyatt AD, Daszak P, et al. (2003) Cryo-archiving of Batrachochytrium dendrobatidis and other chytridiomycetes. Diseases of Aquatic Organisms 56, 59-64.

9. Briggs CJ, Knapp RA, Vredenburg VT (2010) Enzootic and epizootic dynamics of the chytrid fungal pathogen of amphibians. Proceedings of the National Academy of Sciences of the United States of America 107, 9695-9700.

10. Clark K, Karsch-Mizrachi I, Lipman DJ, Ostell J, Sayers EW (2016) GenBank. Nucleic Acids Research 44, D67-72.

11. Daszak P, Cunningham AA, Hyatt AD (2000) Emerging infectious diseases of wildlife-threats to biodiversity and human health. Science 287, 443-449.

12. Daszak P, Cunningham AA, Hyatt AD (2003) Infectious disease and amphibian population declines. Diversity and Distributions 9, 141-150.

13. Earl DA, Vonholdt BM (2012) STRUCTURE HARVESTER: a website and program for visualizing STRUCTURE output and implementing the Evanno method. Conservation Genetics Resources 4, 359-361.

14. Evanno G, Regnaut S, Goudet J (2005) Detecting the number of clusters of individuals using the software STRUCTURE: a simulation study. Molecular Ecology 14, 2611-2620.

15. Farrer RA, Weinert LA, Bielby J, et al. (2011) Multiple emergences of genetically diverse amphibian-infecting chytrids include a globalized hypervirulent recombinant lineage. Proceedings of the National Academy of Sciences of the United States of America 108, $18732-18736$.

16. Fisher MC, Gow NA, Gurr SJ (2016) Tackling emerging fungal threats to animal health, food security and ecosystem resilience. Philosophical Transactions of the Royal Society B: Biological Sciences 371. 
17. Fisher MC, Henk DA, Briggs CJ, et al. (2012) Emerging fungal threats to animal, plant and ecosystem health. Nature 484, 186-194.

18. Forget L, Ustinova J, Wang Z, Huss VAR, Lang BF (2002) Hyaloraphidium curvatum: A linear mitochondrial genome, tRNA editing, and an evolutionary link to lower fungi. Molecular Biology and Evolution 19, 310-319.

19. Gaertner JP, Brown DJ, Mendoza JA, et al. (2012) Geographic variation in Batrachochytrium dendrobatidis occurrence among populations of Acris crepitans blanchardi in Texas, USA. Herpetological Review 43, 274-278.

20. Gaertner JP, Forstner MR, O'Donnell L, Hahn D (2009a) Detection of Batrachochytrium dendrobatidis in endemic salamander species from central Texas. Ecohealth 6, 20-26.

21. Gaertner JP, Gaston MA, Spontak D, Forstner MR, Hahn D (2009b) Seasonal variation in the detection of Batrachochytrium dendrobatidis in a Texas population of Blanchard's cricket frog

22. (Acris crepitans blanchardi). Herpetological Review 40, 184-187.

23. Gaertner JP, McHenry D, Forstner MR, Hahn D (2010) Annual variation of Batrachochytrium dendrobatidis in the Houston toad (Bufo houstonensis) and a sympatric congener (Bufo nebulifer). Herpetological Review 41, 456-459.

24. Goka K, Yokoyama J, Une Y, et al. (2009) Amphibian chytridiomycosis in Japan: distribution, haplotypes and possible route of entry into Japan. Molecular Ecology 18, 4757-4774.

25. Jakobsson M, Rosenberg NA (2007) CLUMPP: a cluster matching and permutation program for dealing with label switching and multimodality in analysis of population structure. Bioinformatics 23, 1801-1806.

26. James TY, Litvintseva AP, Vilgalys R, et al. (2009) Rapid global expansion of the fungal disease chytridiomycosis into declining and healthy amphibian populations. PLoS Pathogens 5, e1000458.

27. James TY, Porter D, Leander CA, Vilgalys R, Longcore JE (2000) Molecular phylogenetics of the Chytridiomycota supports the utility of ultrastructural data in chytrid systematics. Canadian Journal of Botany 78, 336-350.

28. James TY, Toledo LF, Rodder D, et al. (2015) Disentangling host, pathogen, and environmental determinants of a recently emerged wildlife disease: lessons from the first 15 years of amphibian chytridiomycosis research. Ecology and Evolution 5, 4079-4097.

29. Jenkinson TS, Betancourt Roman CM, Lambertini C, et al. (2016) Amphibian-killing chytrid in Brazil comprises both locally endemic and globally expanding populations. Molecular Ecology 25, 2978-2996.

30. Jombart T (2008) adegenet: a R package for the multivariate analysis of genetic markers. Bioinformatics 24, 1403-1405.

31. Kearse M, Moir R, Wilson A, et al. (2012) Geneious Basic: an integrated and extendable desktop software platform for the organization and analysis of sequence data. Bioinformatics 28, 1647-1649.

32. Letcher PM, Powell MJ (2002) A taxonomic summary of Chytriomyces (Chytridiomycota). Mycotaxon 84, 447-487.

33. Letcher PM, Powell MJ, Churchill PF, Chambers JG (2006) Ultrastructural and molecular phylogenetic delineation of a new order, the Rhizophydiales (Chytridiomycota). Mycological Research 110, 898-915. 
34. Lips KR (2016) Overview of chytrid emergence and impacts on amphibians. Philosophical Transactions of the Royal Society B: Biological Sciences 371, 20150465.

35. Lips KR, Brem F, Brenes R, et al. (2006) Emerging infectious disease and the loss of biodiversity in a Neotropical amphibian community. Proceedings of the National Academy of Sciences of the United States of America 103, 3165-3170.

36. Lips KR, Mendelson III JR, Muñoz-Alonso A, Canseco-Márquez L, Mulcahy DG (2004) Amphibian population declines in montane southern Mexico: resurveys of historical localities. Biological Conservation 119, 555-564.

37. Longcore JE (2000) Culture techniques for amphibian chytrids: recognizing, isolating, and culturing Batrachochytrium dendrobatidis from amphibians. In: Getting the Jump on Amphibian Disease: Conference and Workshop Compendium, Cairns, Australia, 26-30, August 2000, 52-54.

38. Longcore JE, Pessier AP, Nichols DK (1999) Batrachochytrium dendrobatidis gen et sp nov, a chytrid pathogenic to amphibians. Mycologia 91, 219-227.

39. Morehouse EA, James TY, Ganley ARD, et al. (2003) Multilocus sequence typing suggests the chytrid pathogen of amphibians is a recently emerged clone. Molecular Ecology 12, 395-403.

40. Morgan JA, Vredenburg VT, Rachowicz LJ, et al. (2007) Population genetics of the frogkilling fungus Batrachochytrium dendrobatidis. Proceedings of the National Academy of Sciences of the United States of America 104, 13845-13850.

41. Nielsen-Gammon JW (2011) The changing climate of Texas. In: The Impact of Global Warming in Texas, 2nd ed. (ed. Schmandt JN, G.R.; Clarkson, J.). University of Texas Press, Austin, TX.

42. Padgett-Flohr GE, Hopkins RL (2009) Batrachochytrium dendrobatidis, a novel pathogen approaching endemism in central California. Diseases of Aquatic Organisms 83, 1-9.

43. Pierce BA, Christiansen JL, Ritzer AL, Jones TA (2010) Ecology of Georgetown salamanders (Eurycea naufragia) within the flow of a spring. Southwestern Naturalist 55, 291-297.

44. Powell MJ, Letcher PM, Chambers JG, Roychoudhury S (2015) A new genus and family for the misclassified chytrid, Rhizophlyctis harderi. Mycologia 107, 419-431.

45. Pritchard JK, Stephens M, Donnelly P (2000) Inference of population structure using multilocus genotype data. Genetics 155, 945-959.

46. Rodriguez D, Becker CG, Pupin NC, Haddad CF, Zamudio KR (2014) Long-term endemism of two highly divergent lineages of the amphibian-killing fungus in the Atlantic Forest of Brazil. Molecular Ecology 23, 774-787.

47. Rosenblum EB, James TY, Zamudio KR, et al. (2013) Complex history of the amphibiankilling chytrid fungus revealed with genome resequencing data. Proceedings of the National Academy of Sciences of the United States of America 110, 9385-9390.

48. Rousset F (2008) Genepop'007: a complete re-implementation of the genepop software for Windows and Linux. Molecular Ecology Resources 8, 103-106.

49. Saenz D, Kavanagh BT, Kwiatkowski MA (2010) Batrachochytrium dendrobatidis detected in amphibians from National Forests in Eastern Texas, USA. Herpetological Review 41, 47.

50. Savage AE, Zamudio KR (2011) MHC genotypes associate with resistance to a frog-killing fungus. Proceedings of the National Academy of Sciences of the United States of America 108, 16705-16710. 
51. Schloegel LM, Toledo LF, Longcore JE, et al. (2012) Novel, panzootic and hybrid genotypes of amphibian chytridiomycosis associated with the bullfrog trade. Molecular Ecology 21, 5162-5177.

52. Talley BL, Muletz CR, Vredenburg VT, Fleischer RC, Lips KR (2015) A century of Batrachochytrium dendrobatidis in Illinois amphibians (1888-1989). Biological Conservation 182, 254-261.

53. Tipton BL, Hibbitts TL, Hibbitts TD, Hibbitts TJ, LaDuc TJ (2012) Texas Amphibians: A Field Guide University of Texas Press, Austin, TX.

54. U.S. climate data (2017) https://www.usclimatedata.com/.

55. USDA/NRCS - National Geospatial Center of Excellence (2015) 1981-2010 Annual Average Maximum Temperature by State. https://tnris.org/datacatalog/entry/precipitation/.

56. Ustinova I, Krienitz L, Huss VAR (2000) Hyaloraphidium curvatum is not a green alga, but a lower fungus; Amoebidium parasiticum is not a fungus, but a member of the DRIPs. Protist 151, 253-262.

57. Velo-Anton G, Rodriguez D, Savage AE, et al. (2012) Amphibian-killing fungus loses genetic diversity as it spreads across the New World. Biological Conservation 146, 213 218.

58. Vredenburg VT, Knapp RA, Tunstall TS, Briggs CJ (2010) Dynamics of an emerging disease drive large-scale amphibian population extinctions. Proceedings of the National Academy of Sciences of the United States of America 107, 9689-9694.

59. Wake DB, Vredenburg VT (2008) Are we in the midst of the sixth mass extinction? A view from the world of amphibians. Proceedings of the National Academy of Sciences of the United States of America 105, 11466-11473.

60. Woodhams DC, Ardipradja K, Alford RA, et al. (2007) Resistance to chytridiomycosis varies among amphibian species and is correlated with skin peptide defenses. Animal Conservation 10, 409-417. 
bioRxiv preprint doi: https://doi.org/10.1101/451385; this version posted October 24, 2018. The copyright holder for this preprint (which was not certified by peer review) is the author/funder, who has granted bioRxiv a license to display the preprint in perpetuity. It is made available under aCC-BY-NC-ND 4.0 International license.

Table 1. Collection sites (abbreviations) for anuran larvae, collection dates, county (Texas, USA), GPS coordinates of specific localities, number of anuran larvae collected, number of chytrid strains isolated (including non-Batrachochytrium dendrobatidis chytrids), and host species from which chytrids were successfully isolated.

\begin{tabular}{lccccccc}
\hline Site & Date & County & Latitude (N) & Longitude (W) & $\begin{array}{c}\text { Larvae } \\
\text { Collected }\end{array}$ & $\begin{array}{c}\text { Chytrid } \\
\text { Isolates }\end{array}$ & Host Species \\
\hline Abby's Pond (AP) & Feb 2016 & Hays & 29.9772 & -97.8984 & 6 & 3 & R. berlandieri \\
Bee Cave (BC) & Mar 2016 & Travis & 30.2542 & -97.9392 & 6 & 4 & R. berlandieri \\
Brackenridge Field Laboratory (BFL) & Mar 2016 & Travis & 30.2837 & -97.7801 & 40 & $11^{\text {a }}$ & R. berlandieri \\
Davy Crockett National Forest (DCNF) & Feb 2016 & Houston & 31.4083 & -95.1667 & 21 & $3^{\text {b }}$ & R. clamitans \\
Griffith League Ranch (GLR) & Dec 2015 & Bastrop & 30.2148 & -97.2576 & 6 & 0 & R. sphenocephala \\
Lakeway (LW) & Mar 2016 & Travis & 30.3766 & -98.0421 & 6 & 6 & R. berlandieri \\
RRR Ranch (RRR) & Mar 2016 Kaufman & 32.5332 & -96.4880 & 47 & 13 & R. sphenocephala \\
Wimberley (WM) & Mar 2016 & Hays & 29.9955 & -98.2163 & 8 & 1 & R. berlandieri \\
\hline Total & \multicolumn{7}{c}{} \\
\hline
\end{tabular}

a includes 1 non- $B d$ isolate

$\mathrm{b}$ all non- $B d$ isolates 
bioRxiv preprint doi: https://doi.org/10.1101/451385; this version posted October 24,2018 . The copyright holder for this preprint (which was not certified by peer review) is the author/funder, who has granted bioRxiv a license to display the preprint in perpetuity. It is made available under aCC-BY-NC-ND 4.0 International license.

Table 2. Genetic diversity of Batrachochytrium dendrobatidis isolates collected in Texas compared to other isolates distributed across the Western Hemisphere. Genetic diversity indices were calculated by averaging across the same six MLST markers.

\begin{tabular}{lcccccc}
\hline & & & & & \multicolumn{2}{c}{ Clone Corrected Data } \\
\cline { 6 - 7 } Region/Population & $\boldsymbol{N}^{\text {a }}$ & MLG $^{\text {b }}$ & $\begin{array}{c}\text { Genotypic } \\
\text { Diversity }\end{array}$ & $\begin{array}{c}\text { Mean } \\
\text { Allelic } \\
\text { Richness }\end{array}$ & $\begin{array}{c}\text { Observed } \\
\text { Heterozygosity }\end{array}$ & $\begin{array}{c}\text { Expected } \\
\text { Heterozygosity }\end{array}$ \\
\hline Temperate America (Bd-GPL) & 57 & 28 & 0.491 & 1.81 & 0.394 & 0.402 \\
$\quad$ Eastern N.A. & 7 & 7 & 1.000 & 1.83 & 0.429 & 0.378 \\
Western N.A. & 13 & 13 & 1.000 & 1.91 & 0.385 & 0.435 \\
$\quad$ Texas & 37 & 15 & 0.405 & 1.72 & 0.387 & 0.348 \\
Tropical America (Bd-GPL) & 92 & 23 & 0.250 & 1.68 & 0.34 & 0.358 \\
$\quad$ Panama & 3 & 3 & 1.000 & 1.59 & 0.333 & 0.259 \\
$\quad$ Southeastern Brazil & 89 & 21 & 0.236 & 1.67 & 0.341 & 0.354 \\
All $\boldsymbol{B} \boldsymbol{d}$-GPL & $\mathbf{1 4 9}$ & $\mathbf{4 7}$ & $\mathbf{0 . 3 1 5}$ & & $\mathbf{0 . 3 7 3}$ & $\mathbf{0 . 4 1 9}$ \\
Hybrids (GPL and $B d$-Brazil) & 3 & 2 & 0.667 & 1.96 & 0.833 & 0.438 \\
Bd-Brazil & $\mathbf{2 5}$ & $\mathbf{7}$ & $\mathbf{0 . 2 8 0}$ & $\mathbf{1 . 3 4}$ & $\mathbf{0 . 2 1 4}$ & $\mathbf{0 . 1 8 9}$ \\
\hline Western Hemisphere & $\mathbf{1 7 7}$ & $\mathbf{5 6}$ & $\mathbf{0 . 3 1 6}$ & & $\mathbf{0 . 3 7 0}$ & $\mathbf{0 . 5 0 6}$ \\
\hline
\end{tabular}

a Sample size.

${ }^{\mathrm{b}}$ Number of multi-locus genotypes 


\section{Figure Legends}

Fig. 1. Sites where anuran larvae were collected and the proportion of chytrid isolates genetically identified to a known $B d$ strain or other chytrid. The background colors indicate mean maximum temperature in the region (USDA/NRCS - National Geospatial Center of Excellence 2015) with the optimal temperature range for $B d$ growth demarcated in the legend (Piotrowski et al. 2004).

Fig. 2. (A) STRUCTURE results for $K=2$ and $K=3$ averaged from five iterations using CLUMPP. Assignment probabilities to the clusters are represented on the $y$-axis, and each bar represents one of the 68 isolates from a six MLST dataset, including 15 isolates collected for this study and 53 additional strains from Schloegel et al. (2012) and Jenkinson et al. (2016). (B) Heat map of pairwise $F_{\mathrm{ST}}$ values by origin calculated from the dataset of $68 \mathrm{Bd}$ isolates, including 15 isolates from central Texas and 53 additional strains from Schloegel et al. (2012) and Jenkinson et al. (2016). 
A

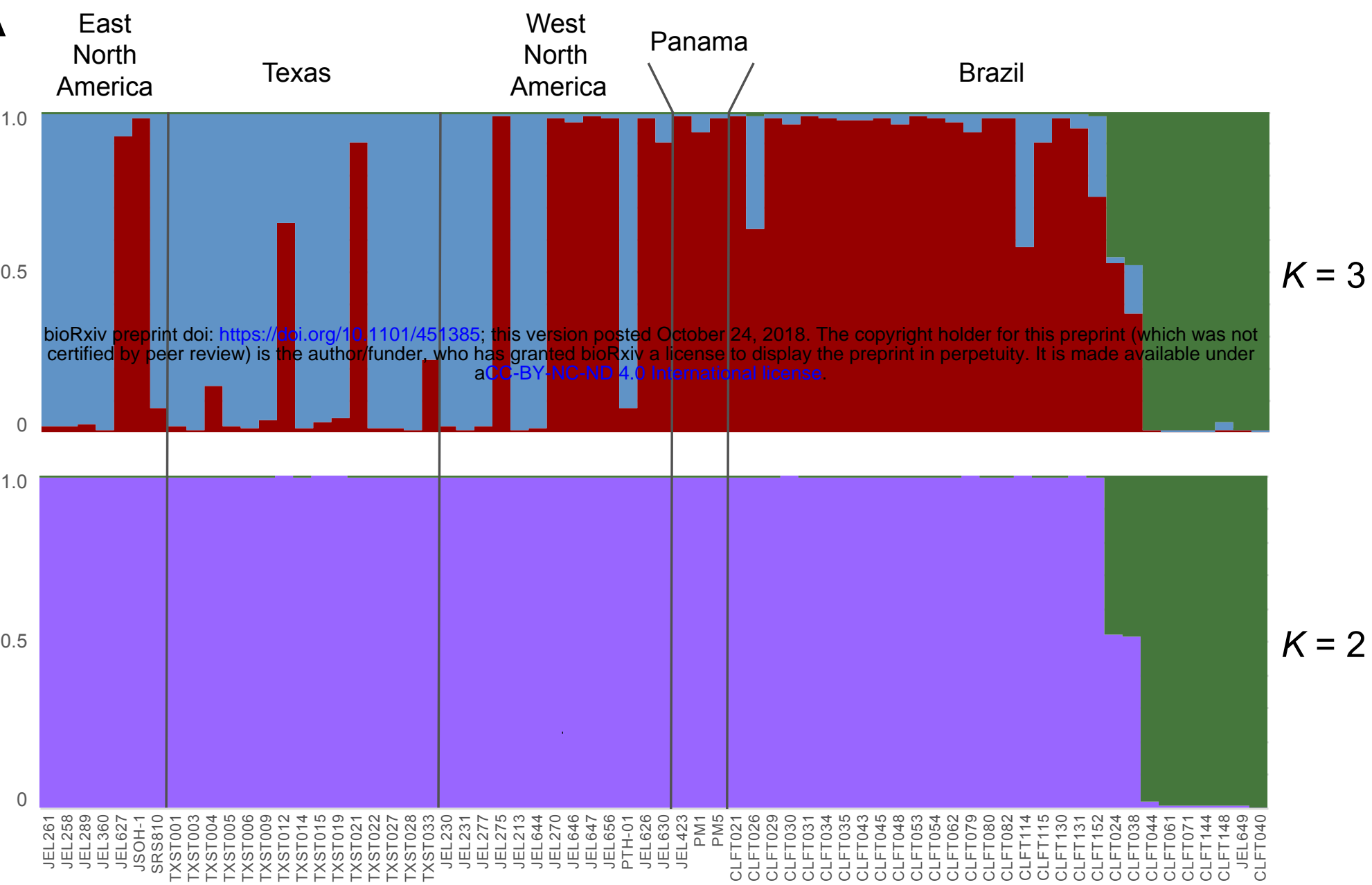

B

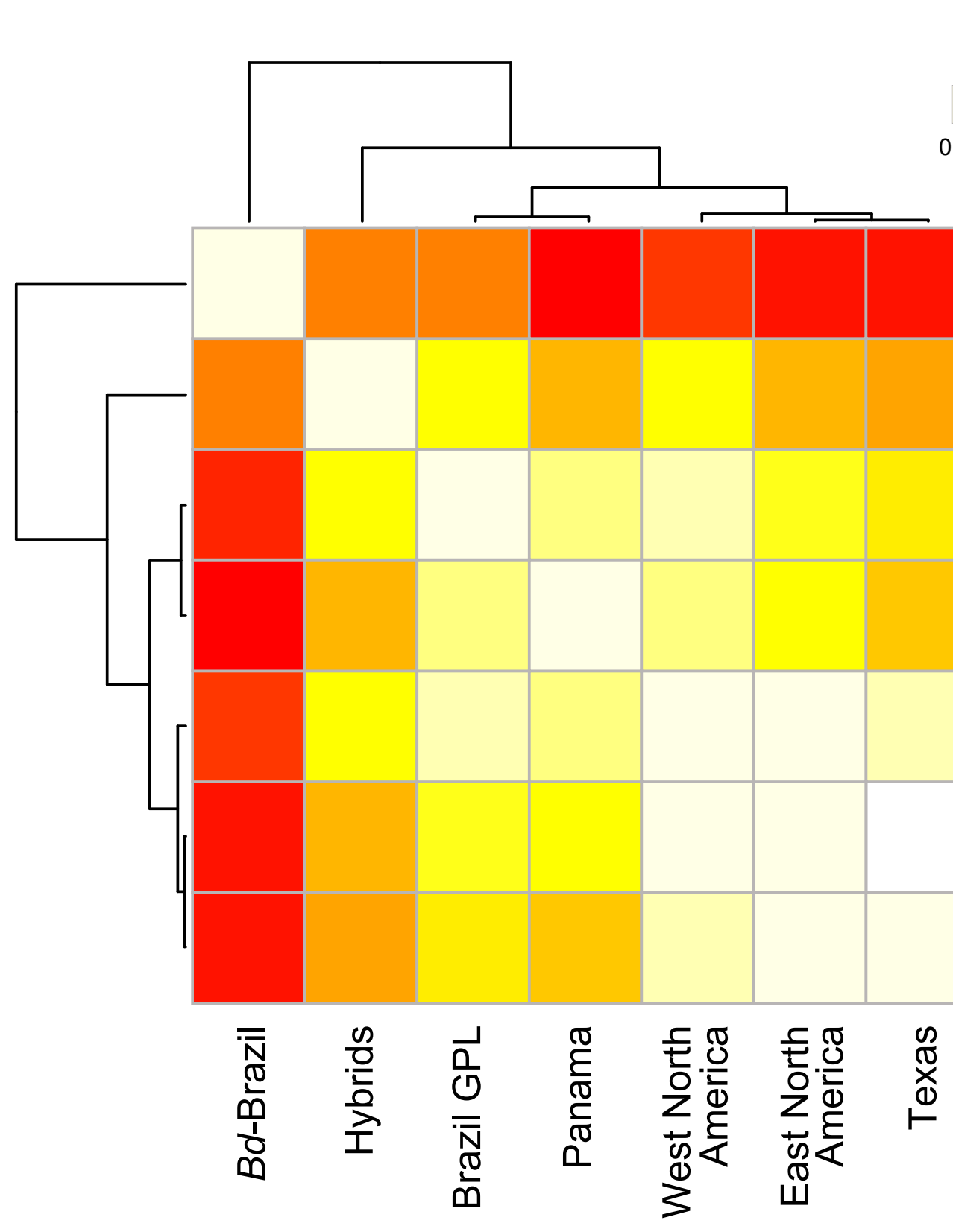

Bd-Brazil

Hybrids

Brazil GPL

Panama

West North

America

East North America

Texas 



\section{APPENDICES}

Appendix 1. Amphibian larvae and adults sampled for this study with collector number (TM = Thomas Marshall, MF = Michael Forstner Tissue Catalog), host species (Rs = Rana sphenocephala, $R b=R$. berlandieri, $R c=R$. clamitans, $P s=P$ seudacris streckeri), host COI GenBank accession number, isolate number, chytrid taxon $(B d=$ Batrachochytrium dendrobatidis, $\mathrm{Uh}=$ Uebelmesseromyces harderi, $\mathrm{Ch}=$ Chytriomyces sp., $\mathrm{Hc}=$ Hyaloraphidium curvatum), chytrid $18 \mathrm{~S}$ GenBank accession number, and locality information.

\begin{tabular}{|c|c|c|c|c|c|c|c|}
\hline Host ID & Host Species & $\mathrm{COI}$ & Isolate ID & Species/Strain & $18 S$ & County & Site \\
\hline TM001 & Rs & MG969227 & & & & Bastrop & GLR \\
\hline TM002 & Rs & MG969228 & & & & Bastrop & GLR \\
\hline TM003 & Rs & MG969229 & & & & Bastrop & GLR \\
\hline TM004 & Rs & MG969230 & & & & Bastrop & GLR \\
\hline TM005 & Rs & MG969231 & & & & Bastrop & GLR \\
\hline TM006 & Rs & MG969232 & & & & Bastrop & GLR \\
\hline TM007 & $\mathrm{Rb}$ & MG969233 & & & & Hays & Abby's Pond \\
\hline TM008 & $\mathrm{Rb}$ & MG969234 & & & & Hays & Abby's Pond \\
\hline TM009 & $\mathrm{Rb}$ & MG969235 & & & & Hays & Abby's Pond \\
\hline TM010 & $\mathrm{Rc}$ & MG969236 & & & & Houston & DCNF \\
\hline TM011 & $\mathrm{Rc}^{\mathrm{a}}$ & & & & & Houston & DCNF \\
\hline TM012 & $\mathrm{Rc}$ & MG969237 & & & & Houston & DCNF \\
\hline TM013 & $\mathrm{Rc}$ & MG969238 & & & & Houston & DCNF \\
\hline TM014 & $\mathrm{Rc}$ & MG969239 & & & & Houston & DCNF \\
\hline TM015 & $\mathrm{Rb}$ & MG969240 & TXST001 & $B d-G P L 1$ & MG979804 & Hays & Abby's Pond \\
\hline TM016 & $\mathrm{Rb}^{\mathrm{a}}$ & & TXST002 & $B d-G P L 1$ & MG979805 & Hays & Abby's Pond \\
\hline TM017 & $\mathrm{Rb}$ & MG969241 & TXST003 & $B d-G P L 1$ & MG979806 & Hays & Abby's Pond \\
\hline TM018 & Rs & MG969242 & & & & Kaufman & RRR Ranch \\
\hline TM019 & Rs & MG969243 & & & & Kaufman & RRR Ranch \\
\hline TM020 & Rs & MG969244 & TXST004 & $B d-G P L 1$ & MG979807 & Kaufman & RRR Ranch \\
\hline TM021 & Rs & MG969245 & & & & Kaufman & RRR Ranch \\
\hline TM022 & Rs & MG969246 & & & & Kaufman & RRR Ranch \\
\hline TM023 & Rs & MG969247 & TXST005 & $B d$-GPL1 & MG979808 & Kaufman & RRR Ranch \\
\hline TM024 & Rs & MG969248 & & & & Kaufman & RRR Ranch \\
\hline TM025 & Rs & MG969249 & & & & Kaufman & RRR Ranch \\
\hline TM026 & Rs & MG969250 & TXST006 & $B d-G P L 1$ & MG979809 & Kaufman & RRR Ranch \\
\hline TM027 & Rs & MG969251 & & & & Kaufman & RRR Ranch \\
\hline TM028 & Rs & MG969252 & TXST007 & $B d$-GPL1 & MG979810 & Kaufman & RRR Ranch \\
\hline TM029 & Rs & MG969253 & TXST008 & $B d-G P L 1$ & MG979811 & Kaufman & RRR Ranch \\
\hline TM030 & Rs & MG969254 & TXST009 & $B d$-GPL1 & MG979812 & Kaufman & RRR Ranch \\
\hline TM031 & Rs & MG969255 & & & & Kaufman & RRR Ranch \\
\hline TM032 & Rs & MG969256 & TXST010 & $B d-G P L 1$ & MG979813 & Kaufman & RRR Ranch \\
\hline TM033 & Rs & MG969257 & TXST011 & $B d$-GPL1 & MG979814 & Kaufman & RRR Ranch \\
\hline TM034 & Rs & MG969258 & TXST012 & $B d-\mathrm{GPL}$ & MG979815 & Kaufman & RRR Ranch \\
\hline TM035 & Rs & MG969259 & & & & Kaufman & RRR Ranch \\
\hline TM036 & Rs & MG969260 & TXST013 & $B d-G P L 1$ & MG979816 & Kaufman & RRR Ranch \\
\hline TM037 & Ps & MG969261 & & & & Travis & Bee Cave \\
\hline TM038 & $\mathrm{Rb}^{\mathrm{a}}$ & & TXST014 & $B d-G P L 1$ & MG979817 & Travis & Bee Cave \\
\hline TM039 & $\mathrm{Rb}^{\mathrm{a}}$ & & TXST015 & $B d-G P L 1$ & MG979818 & Travis & Bee Cave \\
\hline TM040 & Ps & MG969262 & & & & Travis & Bee Cave \\
\hline TM041 & $\mathrm{Rb}$ & MG969263 & TXST016 & $B d$-GPL1 & MG979819 & Hays & Wimberley \\
\hline TM042 & $\mathrm{Rb}$ & MG969264 & & & & Hays & Wimberley \\
\hline TM043 & $\mathrm{Rb}$ & MG969265 & & & & Hays & Wimberley \\
\hline TM044 & $\mathrm{Rb}$ & MG969266 & & & & Hays & Wimberley \\
\hline TM045 & Rs & MG969267 & TXST017 & $B d$-GPL1 & - & Kaufman & RRR Ranch \\
\hline TM046 & $\mathrm{Rs}^{\mathrm{a}}$ & & & & & Kaufman & RRR Ranch \\
\hline TM047 & Rs & MG969268 & & & & Kaufman & RRR Ranch \\
\hline TM048 & $\mathrm{Rs}^{\mathrm{a}}$ & & TXST018 & $B d-G P L 1$ & MG979820 & Kaufman & RRR Ranch \\
\hline
\end{tabular}


bioRxiv preprint doi: https://doi.org/10.1101/451385; this version posted October 24, 2018. The copyright holder for this preprint (which was not certified by peer review) is the author/funder, who has granted bioRxiv a license to display the preprint in perpetuity. It is made available under aCC-BY-NC-ND 4.0 International license.

\begin{tabular}{|c|c|c|c|c|c|c|c|}
\hline TM049 & $\mathrm{Rs}^{\mathrm{a}}$ & & TXST019 & $B d$-GPL1 & MG979821 & Kaufman & RRR Ranch \\
\hline TM050 & Rs & MG969269 & & & & Kaufman & RRR Ranch \\
\hline TM051 & Rs & MG969270 & & & & Kaufman & RRR Ranch \\
\hline TM052 & Rs & MG969271 & & & & Kaufman & RRR Ranch \\
\hline TM053 & Rs & MG969272 & & & & Kaufman & RRR Ranch \\
\hline TM054 & Rs & MG969273 & & & & Kaufman & RRR Ranch \\
\hline TM055 & $\mathrm{Rs}^{\mathrm{a}}$ & & & & & Kaufman & RRR Ranch \\
\hline TM056 & $\mathrm{Rs}^{\mathrm{a}}$ & & & & & Kaufman & RRR Ranch \\
\hline TM057 & $\mathrm{Rs}^{\mathrm{a}}$ & MG969274 & & & & Kaufman & RRR Ranch \\
\hline TM058 & Rs & MG969275 & & & & Kaufman & RRR Ranch \\
\hline TM059 & Rs & MG969276 & & & & Kaufman & RRR Ranch \\
\hline TM060 & Rs & MG969277 & & & & Kaufman & RRR Ranch \\
\hline TM061 & Rs & MG969278 & & & & Kaufman & RRR Ranch \\
\hline TM062 & Rs & MG969279 & & & & Kaufman & RRR Ranch \\
\hline TM064 & $\mathrm{Rs}^{\mathrm{a}}$ & & & & & Kaufman & RRR Ranch \\
\hline TM065 & $\mathrm{Rs}^{\mathrm{a}}$ & & & & & Kaufman & RRR Ranch \\
\hline TM066 & Rs & MG969280 & & & & Kaufman & RRR Ranch \\
\hline TM067 & Rs & MG969281 & & & & Kaufman & RRR Ranch \\
\hline TM068 & Rs & MG969282 & & & & Kaufman & RRR Ranch \\
\hline TM069 & $\mathrm{Rs}^{\mathrm{a}}$ & & & & & Kaufman & RRR Ranch \\
\hline TM070 & $\mathrm{Rs}^{\mathrm{a}}$ & & & & & Kaufman & RRR Ranch \\
\hline TM071 & $\mathrm{Rs}^{\mathrm{a}}$ & & & & & Kaufman & RRR Ranch \\
\hline TM072 & $\mathrm{Rs}^{\mathrm{a}}$ & & & & & Kaufman & RRR Ranch \\
\hline TM074 & $\mathrm{Rb}$ & MG969283 & TXST020 & $B d$-GPL1 & MG979822 & Travis & BFL \\
\hline TM075 & $\mathrm{Rb}$ & MG969284 & TXST021 & $B d$-GPL2 & MG979823 & Travis & BFL \\
\hline TM076 & $\mathrm{Rb}$ & MG969285 & TXST022 & $B d$-GPL1 & MG979824 & Travis & BFL \\
\hline TM077 & $\mathrm{Rb}$ & MG969286 & & & & Travis & BFL \\
\hline TM078 & $\mathrm{Rb}$ & MG969287 & & & & Travis & BFL \\
\hline ТМ079 & $\mathrm{Rb}$ & MG969288 & & & & Travis & BFL \\
\hline TM080 & $\mathrm{Rb}$ & MG969289 & & & & Travis & BFL \\
\hline TM081 & $\mathrm{Rb}$ & MG969290 & TXST023 & $B d$-GPL1 & MG979825 & Travis & BFL \\
\hline TM082 & $\mathrm{Rb}$ & MG969291 & & & & Travis & BFL \\
\hline TM083 & $\mathrm{Rb}$ & MG969292 & & & & Travis & BFL \\
\hline TM084 & $\mathrm{Rb}$ & MG969293 & & & & Travis & BFL \\
\hline TM085 & $\mathrm{Rb}$ & MG969294 & & & & Travis & BFL \\
\hline TM086 & $\mathrm{Rb}$ & MG969295 & TXST024 & $B d$-GPL1 & MG979826 & Travis & BFL \\
\hline TM087 & $\mathrm{Rb}$ & MG969296 & & & & Travis & BFL \\
\hline TM088 & $\mathrm{Rb}$ & MG969297 & TXST025 & $B d$-GPL1 & MG979827 & Travis & BFL \\
\hline TM089 & $\mathrm{Rb}$ & MG969298 & TXST038 & $H c$ & MG979828 & Travis & BFL \\
\hline TM090 & $\mathrm{Rb}$ & MG969299 & TXST026 & $B d$-GPL2 & MG979829 & Travis & BFL \\
\hline TM091 & $\mathrm{Rb}$ & MG969300 & TXST027 & $B d$-GPL1 & MG979830 & Travis & Lakeway \\
\hline TM092 & $\mathrm{Rb}$ & MG969301 & TXST028 & $B d$-GPL1 & MG979831 & Travis & Lakeway \\
\hline TM093 & $\mathrm{Rb}$ & MG969302 & TXST029 & $B d$-GPL1 & MG979832 & Travis & Lakeway \\
\hline TM094 & $\mathrm{Rb}$ & MG969303 & TXST030 & $B d$-GPL1 & MG979833 & Travis & Lakeway \\
\hline TM095 & $\mathrm{Rb}$ & MG969304 & TXST031 & $B d$-GPL1 & MG979834 & Travis & Lakeway \\
\hline TM096 & $\mathrm{Rb}$ & MG969305 & TXST032 & $B d$-GPL1 & MG979835 & Travis & Lakeway \\
\hline TM097 & $\mathrm{Rb}$ & MG969306 & & & & Travis & BFL \\
\hline TM098 & $\mathrm{Rc}$ & MG969307 & & & & Houston & DCNF \\
\hline TM099 & $\mathrm{Rc}$ & MG969308 & & & & Houston & DCNF \\
\hline TM100 & $\mathrm{Rc}$ & MG969309 & & & & Houston & DCNF \\
\hline TM101 & $\mathrm{Rc}^{\mathrm{a}}$ & & & & & Houston & DCNF \\
\hline TM102 & $\mathrm{Rc}$ & MG969310 & & & & Houston & DCNF \\
\hline TM103 & $\mathrm{Rc}$ & MG969311 & & & & Houston & DCNF \\
\hline TM104 & $\mathrm{Rc}$ & MG969312 & & & & Houston & DCNF \\
\hline TM105 & $\mathrm{Rc}$ & MG969313 & & & & Houston & DCNF \\
\hline TM106 & $\mathrm{Rc}$ & MG969314 & & & & Houston & DCNF \\
\hline TM107 & $\mathrm{Rc}$ & MG969315 & & & & Houston & DCNF \\
\hline TM108 & $\mathrm{Rc}$ & MG969316 & TXST039 & $U h$ & MG979836 & Houston & DCNF \\
\hline TM109a & $\mathrm{Rc}$ & MG969317 & TXST040 & $U h$ & MG979837 & Houston & DCNF \\
\hline TM109b & $\mathrm{Rc}$ & MG969318 & TXST041 & $C h$ & MG979838 & Houston & DCNF \\
\hline TM110 & $\mathrm{Rc}$ & MG969319 & & & & Houston & DCNF \\
\hline TM111 & $\mathrm{Rc}$ & MG969320 & & & & Houston & DCNF \\
\hline
\end{tabular}


bioRxiv preprint doi: https://doi.org/10.1101/451385; this version posted October 24,2018 . The copyright holder for this preprint (which was not certified by peer review) is the author/funder, who has granted bioRxiv a license to display the preprint in perpetuity. It is made available under aCC-BY-NC-ND 4.0 International license.

\begin{tabular}{|c|c|c|c|c|c|c|c|}
\hline TM112 & $\mathrm{Rc}$ & MG969310 & & & & Houston & DCNF \\
\hline TM113 & $\mathrm{Rc}^{\mathrm{a}}$ & & & & & Houston & DCNF \\
\hline TM114 & $\mathrm{Rb}$ & MG969321 & & & & Travis & BFL \\
\hline TM115 & $\mathrm{Rb}$ & MG969322 & & & & Travis & BFL \\
\hline TM116 & $\mathrm{Rb}$ & MG969323 & & & & Travis & BFL \\
\hline TM117 & $\mathrm{Rb}^{\mathrm{a}}$ & & & & & Travis & BFL \\
\hline TM118 & $\mathrm{Rb}$ & MG969324 & & & & Travis & $\mathrm{BFL}$ \\
\hline TM119 & $\mathrm{Rb}$ & MG969325 & & & & Travis & BFL \\
\hline TM120 & $\mathrm{Rb}$ & MG969326 & & & & Travis & BFL \\
\hline TM121 & $\mathrm{Rb}$ & MG969327 & TXST033 & $B d-\mathrm{GPL}$ & MG979839 & Travis & BFL \\
\hline TM122 & $\mathrm{Rb}$ & MG969328 & TXST034 & $B d$-GPL1 & MG979840 & Travis & BFL \\
\hline TM123 & $\mathrm{Rb}$ & MG969329 & & & & Travis & BFL \\
\hline TM124 & $\mathrm{Rb}$ & MG969330 & & & & Travis & BFL \\
\hline TM125 & $\mathrm{Rb}$ & MG969331 & TXST035 & $B d$-GPL2 & MG979841 & Travis & BFL \\
\hline TM126 & $\mathrm{Rb}$ & MG969332 & & & & Travis & BFL \\
\hline TM127 & $\mathrm{Rb}$ & MG969333 & TXST036 & $B d$-GPL1 & - & Travis & Bee Cave \\
\hline TM128 & $\mathrm{Rb}$ & MG969334 & TXST037 & $B d$-GPL1 & MG979842 & Travis & Bee Cave \\
\hline TM129 & $\mathrm{Rb}$ & MG969335 & & & & Hays & Wimberley \\
\hline TM130 & $\mathrm{Rb}$ & MG969336 & & & & Hays & Wimberley \\
\hline TM131 & $\mathrm{Rb}$ & MG969337 & & & & Hays & Wimberley \\
\hline TM132 & $\mathrm{Rb}$ & MG969338 & & & & Hays & Wimberley \\
\hline TM133 & $\mathrm{Rb}$ & MG969339 & & & & Travis & BFL \\
\hline TM134 & $\mathrm{Rb}$ & MG969340 & & & & Travis & BFL \\
\hline TM135 & $\mathrm{Rb}$ & MG969341 & & & & Travis & BFL \\
\hline TM136 & $\mathrm{Rb}$ & MG969342 & & & & Travis & BFL \\
\hline TM137 & $\mathrm{Rb}$ & MG969343 & & & & Travis & BFL \\
\hline TM138 & $\mathrm{Rb}$ & MG969344 & & & & Travis & BFL \\
\hline TM139 & $\mathrm{Rb}$ & MG969345 & & & & Travis & BFL \\
\hline TM140 & $\mathrm{Rb}$ & MG969346 & & & & Travis & BFL \\
\hline TM141 & $\mathrm{Rb}$ & MG969347 & & & & Travis & BFL \\
\hline MF8122 b & $\mathrm{Rb}$ & MG969220 & & & & Bastrop & $30.201034,-97.221376$ \\
\hline MF8124 b & $\mathrm{Rb}$ & MG969221 & & & & Bastrop & $30.201034,-97.221378$ \\
\hline MF $17750^{b}$ & $\mathrm{Rb}$ & MG969222 & & & & Brewster & $29.1796932,-102.9955709$ \\
\hline MF17751 b & $\mathrm{Rb}$ & MG969223 & & & & Brewster & $29.1796932,-102.9955709$ \\
\hline MF17752b & $\mathrm{Rb}$ & MG969224 & & & & Brewster & $29.1796932,-102.9955709$ \\
\hline MF17753 b & $\mathrm{Rb}$ & MG969225 & & & & Brewster & $29.1796932,-102.9955709$ \\
\hline MF21852 b & $\mathrm{Rb}$ & MG969226 & & & & Jim Hogg & $27.1633606,-98.54593658$ \\
\hline
\end{tabular}

${ }^{a}$ Host species assignment based on morphology and collection locality.

b Adult Rana berlanderi used as genetic references. 
Appendix 2. $B d$ Isolates Analyzed for this Study with Lineage, Location Collected, and Original Publication. This table includes the 68 isolates, including 15 Texas isolates, included in the STRUCTURE and pairwise $F_{\mathrm{ST}}$ analyses using six MLST markers.

\begin{tabular}{|c|c|c|c|}
\hline Isolate & Lineage & Location & Source \\
\hline TXST001 & GPL1 & Texas & Collected for this study \\
\hline TXST003 & GPL1 & Texas & Collected for this study \\
\hline TXST004 & GPL1 & Texas & Collected for this study \\
\hline TXST005 & GPL1 & Texas & Collected for this study \\
\hline TXST006 & GPL1 & Texas & Collected for this study \\
\hline TXST009 & GPL1 & Texas & Collected for this study \\
\hline TXST012 & GPL & Texas & Collected for this study \\
\hline TXST014 & GPL1 & Texas & Collected for this study \\
\hline TXST015 & GPL1 & Texas & Collected for this study \\
\hline TXST019 & GPL1 & Texas & Collected for this study \\
\hline TXST021 & GPL2 & Texas & Collected for this study \\
\hline TXST022 & GPL1 & Texas & Collected for this study \\
\hline TXST027 & GPL1 & Texas & Collected for this study \\
\hline TXST028 & GPL1 & Texas & Collected for this study \\
\hline TXST033 & GPL & Texas & Collected for this study \\
\hline JEL213 & GPL1 & W. North America & Schloegel et al. 2012 \\
\hline JEL230 & GPL1 & W. North America & Schloegel et al. 2012 \\
\hline JEL231 & GPL1 & W. North America & Schloegel et al. 2012 \\
\hline JEL258 & GPL1 & E. North America & Schloegel et al. 2012 \\
\hline JEL261 & GPL1 & E. North America & Schloegel et al. 2012 \\
\hline JEL270 & GPL2 & W. North America & Schloegel et al. 2012 \\
\hline JEL275 & GPL2 & W. North America & Schloegel et al. 2012 \\
\hline JEL277 & GPL1 & W. North America & Schloegel et al. 2012 \\
\hline JEL289 & GPL1 & E. North America & Schloegel et al. 2012 \\
\hline JEL360 & GPL1 & E. North America & Schloegel et al. 2012 \\
\hline JEL423 & GPL2 & Panama & Schloegel et al. 2012 \\
\hline JEL626 & GPL2 & W. North America & Schloegel et al. 2012 \\
\hline JEL627 & GPL2 & E. North America & Schloegel et al. 2012 \\
\hline JEL630 & GPL2 & W. North America & Schloegel et al. 2012 \\
\hline JEL644 & GPL1 & W. North America & Schloegel et al. 2012 \\
\hline JEL646 & GPL2 & W. North America & Schloegel et al. 2012 \\
\hline JEL647 & GPL2 & W. North America & Schloegel et al. 2012 \\
\hline JEL656 & GPL2 & W. North America & Schloegel et al. 2012 \\
\hline JSOH-1 & GPL2 & E. North America & Schloegel et al. 2012 \\
\hline PM1 & GPL2 & Panama & Schloegel et al. 2012 \\
\hline PM5 & GPL2 & Panama & Schloegel et al. 2012 \\
\hline PTH-001 & GPL1 & W. North America & Schloegel et al. 2012 \\
\hline SRS810 & GPL1 & E. North America & Schloegel et al. 2012 \\
\hline CLFT026 & GPL & Brazil & Jenkinson et al. 2016 \\
\hline CLFT029 & GPL2 & Brazil & Jenkinson et al. 2016 \\
\hline
\end{tabular}




\begin{tabular}{lccc} 
CLFT030 & GPL2 & Brazil & Jenkinson et al. 2016 \\
CLFT031 & GPL2 & Brazil & Jenkinson et al. 2016 \\
CLFT034 & GPL2 & Brazil & Jenkinson et al. 2016 \\
CLFT035 & GPL2 & Brazil & Jenkinson et al. 2016 \\
CLFT038 & Hybrid & Brazil & Jenkinson et al. 2016 \\
CLFT040 & Bd-Brazil & Brazil & Jenkinson et al. 2016 \\
CLFT043 & GPL2 & Brazil & Jenkinson et al. 2016 \\
CLFT044 & Bd-Brazil & Brazil & Jenkinson et al. 2016 \\
CLFT045 & GPL2 & Brazil & Jenkinson et al. 2016 \\
CLFT048 & GPL2 & Brazil & Jenkinson et al. 2016 \\
CLFT053 & GPL2 & Brazil & Jenkinson et al. 2016 \\
CLFT054 & GPL2 & Brazil & Jenkinson et al. 2016 \\
CLFT061 & Bd-Brazil & Brazil & Jenkinson et al. 2016 \\
CLFT062 & GPL2 & Brazil & Jenkinson et al. 2016 \\
CLFT071 & Bd-Brazil & Brazil & Jenkinson et al. 2016 \\
CLFT079 & GPL2 & Brazil & Jenkinson et al. 2016 \\
CLFT080 & GPL2 & Brazil & Jenkinson et al. 2016 \\
CLFT082 & GPL2 & Brazil & Jenkinson et al. 2016 \\
CLFT114 & GPL & Brazil & Jenkinson et al. 2016 \\
CLFT115 & GPL2 & Brazil & Jenkinson et al. 2016 \\
CLFT130 & GPL2 & Brazil & Jenkinson et al. 2016 \\
CLFT131 & GPL2 & Brazil & Jenkinson et al. 2016 \\
CLFT144 & $B d$-Brazil & Brazil & Jenkinson et al. 2016 \\
CLFT148 & $B d$-Brazil & Brazil & Jenkinson et al. 2016 \\
CLFT152 & GPL & Brazil & Jenkinson et al. 2016 \\
\hline & & &
\end{tabular}

